\title{
PODER, PENE, ERECCIÓN, CASTRACIÓN Y MACHISMO EN LA OBRA DE MARIO VARGAS LLOSA
}

\author{
Iván Thays
}

En este artículo se sostiene que el eje de la narrativa de Mario Vargas Llosa gira en torno al poder y sus relaciones con los miembros de la sociedad, entre conspiradores y resignados. A su vez, se propone que la lucha por el poder es consecuencia de la convivencia en una sociedad machista, más específicamente falocéntrica, donde los "machos" buscan perpetuarse en el poder y ejercerlo de manera autoritaria y arbitraria, con referentes sexuales masculinos constantes (desde la erección hasta la castración), mientras que los conspiradores tratan de librarse de ese autoritarismo y ganar, a veces también a través de la violencia, su soberanía, su individualidad y su libertad. El artículo alude a la teoría de los demonios personales de Vargas Llosa y al exorcismo del tema del padre ausente. Recorre la obra del autor y se centra en la novela que, al parecer, es la más pertinente para comentar ese exorcismo público: $L a$ fiesta del Chivo.

IvÁN Thays (Lima, 1968). Escritor. Ha publicado el libro de cuentos Las fotografias de Frances Farmer, y las novelas Escena de caza, El viaje interior, La disciplina de la vanidad, Un lugar llamado Oreja de perro y, recientemente, Un sueño fugaz. Fue finalista del Premio Herralde de Novela 2008 y recibió el premio Príncipe Claus 2001 por su contribución cultural. Dirigió el programa de TV en Lima "Vano Oficio" y actualmente es administrador del blog literario Moleskine Literario. 


\section{Macho}

Alguna vez, Mario Vargas Llosa inició un discurso pidiendo excusas por el exabrupto. Dijo entonces que la novela era el género mayor. También yo quisiera iniciar este ensayo con un exabrupto. Deseo afirmar categóricamente que la literatura del llamado Boom Narrativo Latinoamericano es machista. Falocéntrico si gustan, para abusar una palabra fea y pedante. Pero sobre todo, una literatura de "machos".

Me refiero, desde luego, a la actitud de los escritores ante la prensa y el público en general. El terno, la corbata de seda, el compromiso político, el cabello apenas despeinado, la esposa perfecta proyectándose como la mujer latinoamericana que se rige bajo la regla: "detrás de cada gran hombre hay una gran mujer".

Ni siquiera voy a insistir demasiado aquí en la infortunada frase de Julio Cortázar sobre los lectores machos (activos, transgresores, lúdicos) y las lectoras hembras (pasivas, conservadoras, lineales). No hace falta. Como anécdota, en todo caso, es insuperable aquella de la que nos hemos enterado hace poco por Pilar Donoso (en ese libro curioso llamado Correr un tupido velo), en el libro que le dedica a su padre, según la cual fue invitada a un programa sobre hijos de famosos y José Donoso le pidió, me imagino que con mucha vergüenza, que por favor, cuando le interrogasen por los hobbies de sus padres, no comentase en el programa su gusto por la decoración.

No he leído las cartas de Donoso, no sé si su aparente homosexualidad fue una etapa, una latencia o una represión, y Pilar Donoso nunca lo dice explícitamente, pero es seguro que José Donoso estaba muy preocupado (demasiado para mi gusto) en encajar bien en la foto del Boom Narrativo Latinoamericano, y para eso desde luego tenía que aparentar ser bastante macho.

Una fotografía donde no encaja, por ejemplo, Manuel Puig y su militancia homosexual y sus amantes impresentables o sus novelas "ligeras" con tanta referencia a actrices de Hollywood y gays convertidos por amor al comunismo (y comunistas machos que aceptan hacer el amor con homosexuales como un acto solidario). No, Puig queda muy mal en esa foto.

Hablando de fotos, podríamos hablar, sí, de una muy interesante. Podríamos referirnos, por ejemplo, al célebre 12 de febrero de 1976, cuando en la cola de un cine en Ciudad de México Mario Vargas Llosa 
le encajó un golpe a Gabriel García Márquez, que quedó inmortalizado dos días después por el fotógrafo Rodrigo Moya. Las versiones sobre aquel puñetazo suelen desviarse hacia las diferencias políticas, pero algunos biógrafos (el amigo peruano de Vargas Llosa, el periodista Francisco Igartúa, por ejemplo, o el biógrafo no oficial pero tolerado de García Márquez, Gerarld Clark) han sido muy explícitos en afirmar que el problema concreto fueron los celos de Mario Vargas Llosa por algunos comentarios que García Márquez le hizo a Patricia Vargas Llosa. "Esto es por lo que le dijiste a Patricia" o "Esto es por lo que le hiciste a Patricia", al parecer fueron las palabras que se dijeron antes del puñetazo.

Más allá del chisme, que se mantendrá así dado el pacto de ambos escritores en no decir nunca nada al respecto y "dejárselo a los biógrafos", lo cierto es que la respuesta de Mario Vargas Llosa fue la de un macho.

Sin embargo, más interesante que estas anécdotas es reconocer que la literatura del boom describe el machismo no necesariamente como una expresión de su identidad como autores, sino de la sociedad que buscan representar. Y esa representación, en el caso de Vargas Llosa, se convierte en una obsesión por el detalle, un auténtico realismo topográfico, con sendas investigaciones que preceden a la escritura de la novela. Desde luego, la sociedad que retratan en sus novelas es machista, ya sea rural con personajes como Pedro Páramo o los Buendía, o urbana como los misóginos protagonistas de Onetti y Santa María, donde las mujeres están locas o son prostitutas y los hombres pueden ser unos fracasados pero al fin sobrevivientes.

Mario Vargas Llosa representa, en el ala realista, el mejor testimonio del machismo que impera en la sociedad latinoamericana. En sus novelas, el conflicto del poder es en realidad una lucha entre dos machos por asumir el liderazgo de la manada. No por nada un libro suyo se titula Los cachorros y en otro título se enfatiza la palabra "perros" para nombrar a jóvenes a punto de ingresar a patadas, o mejor a dentelladas, en la sociedad.

El tema de la lucha por el poder, que enfrenta a adolescentes contra sus superiores (padres, profesores, gobernantes), está presente desde el primer cuento que publicó Vargas Llosa, titulado "Los jefes", y sigue estándolo en sus últimas novelas, como El sueño del celta. Desde luego, el tema no se ha mantenido inmóvil sino que ha ido desarrollándose, complejizándose, envolviendo otros temas con él, conviviendo con 
otras obsesiones suyas como la de la libertad, la civilización y la ficción. Vargas Llosa ha escrito novelas realistas, novelas históricas, novelas eróticas, novelas policiales y hasta novelas políticas. Y en todas ellas se pueden rastrear, como marca indeleble, sus temas (o "demonios" como los califica él) surgidos en la adolescencia, donde los "jefes" y su poder inexplicable, arbitrario y autoritario, lo obligaban a rebelarse.

Limitándonos solo al tema del poder, sin embargo, debemos destacar dos elementos claves que pueden servirnos de guía para entrar en el mundo machista retratado por Vargas Llosa:

a) La biografía personal del autor, y su relación con el padre, como un revulsivo o un gran movilizador del tema;

b) La importancia del pene y la erección como símbolo del poder.

Pero antes de entrar de lleno a estos dos aspectos en la obra de Vargas Llosa, y en especial en la novela La fiesta del Chivo donde el desarrollo de estos ítemes alcanza una excelencia muy superior al de las otras novelas, debo hacer un breve paréntesis que me ayudará a enfocar el tema.

\section{Un paréntesis moraviano}

En 1988 Alberto Moravia publicó una de sus novelas más célebres, aunque no tan bien recibida por la crítica, llamada El hombre que mira. La novela enfrenta a un mediocre profesor de literatura con su padre, un eminente profesor de ciencia, que está postrado en una cama. Ambos conviven en la misma casa junto con la esposa del profesor de literatura, quien al parecer mantiene relaciones adúlteras con el padre de su esposo.

El protagonista es un típico personaje moraviano, un escéptico, demasiado racional y, por tanto, impedido de asumir una actitud o una decisión. Prefiere vivir en el mundo de las hipótesis, de las elucubraciones, como si fuera un constante paciente en el diván de su terapeuta. En el caso concreto de esta novela, esa pasividad lo conduce a una condición sexual limitante: es un voyeur.

Concretamente, es un voyeurista en sus relaciones sexuales tanto como lo es en su vida. Un simple espectador. Mientras tanto, aun postrado en la cama, su padre se presenta como un macho alfa, un cabeza de manada, no solo enrostrando su éxito profesional a su hijo sino, además, su éxito con las mujeres. La posible relación de su nuera con 
él casi se justifica por ese motivo: él es el macho de la casa, y por tanto debe tener privilegio sobre la hembra de su hijo. Y su hijo, mientras no pueda asumir su rol de macho y luchar contra su padre, solo puede quedarse relegado al mundo del observador o en el "hombre que mira", como lo califica el título de la novela.

Lo más impactante en esta lucha de poderes entre padre e hijo, y lo que hace pertinente este paréntesis moraviano, es que en la novela se explicita que el padre tiene un pene enorme y aun hábil, un verdadero cetro de poder, que deja a su hijo (presumiblemente no tan bien dotado) fuera de batalla. La relación de poder no es una lucha equilibrada sino que está perdida de antemano: es más poderoso el que tiene el pene más grande y activo.

El rol pasivo, voyeur, de su hijo se explica así en término falocéntricos. Alrededor del tamaño del falo gira tanto el éxito con las mujeres, y el éxito social del padre, como el fracaso sentimental y social del hijo.

Desde luego, el tema no es biológico sino psicológico. Tengo entendido que los requisitos para ser el macho de la manada, en el mundo animal, no pasa por las dimensiones del pene sino por otros signos exteriores como la abundancia de pelo, la fuerza física y la estatura. Somos nosotros, quienes habitamos en sociedades machistas y falocéntricas, los que hemos convertido el tamaño del pene en un tema de extrema importancia, reverencial, al mismo tiempo que en un motivo de competencia, además de un espectro que aparece en la mayor parte de fantasías y fobias sexuales masculinas.

La novela de Moravia lo expone con toda claridad. Las novelas de Vargas Llosa, aunque no son tan expositivas, también permiten notar esa situación.

\section{El padre de Mario Vargas Llosa}

Para poder entender con mayor agudeza el tema de la lucha de poder en la obra de Mario Vargas Llosa debemos fijarnos, sin lugar a dudas, en su biografía. Y no solo porque su biografía puede echar luces sobre el origen del tema, sino porque el propio Vargas Llosa ha defendido muchas veces el acto de escritura como una revancha contra las fracturas del mundo. En el libro que le dedicó a Gabriel García Márquez, calificó al escritor como "deicida" o suplantador de Dios. La realidad 
que le es desagradable es transformada en una realidad nueva, que tiene a su favor el orden y la coherencia, y no el azar y la oscuridad en que nos quedamos en un mundo sin Dios.

Pero para que el "deicida" nazca, para que el autor de ficciones decida transgredir la realidad-real y elaborar una propia realidad, una ficción cuestionadora y totalizante, hace falta que primero descubra (aunque sea de manera inconsciente) que existe una fractura con la realidad, algo que no funciona bien. A esas rupturas con la realidad las ha calificado en innumerables artículos como "demonios" e incluso los ha dividido en personales, culturales e históricos.

Rosa Boldori, en el libro de ensayos de 1974, Mario Vargas Llosa: un escritor y sus demonios, resumió así qué son los demonios según el autor: "sueños, mitos, cuya presencia o cuya ausencia, cuya vida o cuya muerte lo enemistaron con la realidad". Luego agregará que al escribir una ficción los autores tratan de "recuperar y exorcizar" esos demonios.

Los demonios, pues, serán la fuente de inspiración inicial y el tema que se desarrolla, de manera consciente o inconsciente, en las ficciones. Y perdura hasta que el demonio haya sido completamente exorcizado (y aun así, añado, a veces incluso persiste el demonio, mutando de piel quizá, pero insistente en seguir generando incomodidades que impulsan a la ficción).

Desde luego, la teoría de los demonios de Vargas Llosa no debe llevarnos a considerar que los escritores son, necesariamente, autobiográficos. La ecuación no es tan simple. Al contrario, los autores comprenden que la única manera de vencer a esos demonios es llevarlos a un terreno donde ellos no pueden triunfar, el terreno del orden y de la contingencia, es decir el territorio de la ficción. 2002:

Dice en el prólogo a La verdad de las mentiras, publicado en

La fantasía de que estamos dotados es un don demoniaco.

Está continuamente abriendo un abismo entre lo que somos y lo que quisiéramos ser, entre lo que tenemos y lo que deseamos.

Pero la imaginación ha concebido un astuto y sutil paliativo para ese divorcio inevitable entre nuestra realidad limitada y nuestros apetitos desmedidos: la ficción. Gracias a ella somos más y somos otros sin dejar de ser los mismos. [...] La ficción enriquece su existencia, la completa y, transitoriamente, la compensa de esa trágica condición que es la nuestra: la de desear y soñar siempre más de lo que podemos alcanzar. 
Y más adelante, en el mismo libro, afirmará con contundencia:

[...] jugar a las mentiras, como juegan el autor de una ficción y su lector, a las mentiras que ellos mismo fabrican bajo el imperio de sus demonios personales, es una manera de afirmar la soberanía individual y de defenderla cuando está amenazada; de preservar un espacio propio de libertad, una ciudadela fuera del control del poder y de las interferencias de los otros, en el interior de la cual somos de verdad los soberanos de nuestro destino.

Ambas citas son muy notables en su manera de darle sentido a la ficción, un sentido que tiene que ver directamente no solo con el exorcismo del demonio sino con el posterior beneficio de que, al exorcizarlo, uno no solo se libra de él sino que reafirma su soberanía, su libertad y su individualidad. Es decir, derrota al poder superior que pretende suprimir ese espacio propio.

Siendo así, la pregunta obvia es: ¿Cuál es ese demonio personal al que Mario Vargas Llosa debe exorcizar para vivir en libertad, afirmar su soberanía y vencer al poder superior que pretende imponerse sobre él de manera arbitraria?

Es entonces que la sombra de su padre aparece como una proyección muy intensa y fuerte sobre sus primeras novelas. Y, mutando en un fantasma menos aterrador, aparece también en el resto de sus obras donde la defensa de la libertad y la individualidad se convierte en un tema obsesivo.

¿Y cuál es la historia del padre? Todas las biografías, incluso las más breves y ligeras, ponen hincapié en la relación de Mario Vargas Llosa y su padre. El asunto se puede resumir más o menos así: la madre del autor se había separado de su esposo cuando nació el hijo en Arequipa, al sur del país. Durante años, para ocultarle la separación, al pequeño Mario le hicieron creer que su padre había muerto (él se lo imaginaba como un militar debido a una foto en que aparece vestido de aviador) y se acostumbró a una vida donde él era el único varón, el elegido, rodeado de su madre, su abuela y sus tías, el séquito de un abuelo que vivió con un cargo de administrador de una hacienda en Cochabamba, Bolivia, y luego, con un cargo en la prefectura de Piura, una ciudad pequeña y calurosa al norte del país. 
Cuando Mario Vargas Llosa contaba con diez años de edad (probablemente a inicios de 1947) el padre ausente apareció, de manera súbita, en su vida. Había decidido volver con su mujer y la madre de su hijo, y se llevó a ambos a Lima de manera contundente, inconsulta, alejando al niño de lo que había sido su harem familiar y, además, obligándolo a aceptar que su padre que creía muerto, estaba vivo. Apenas podemos imaginar el shock que pueden ocasionar estos dos hechos simultáneos en la cabeza de un niño, más aun en uno tan sensible como Mario Vargas Llosa. Pero aun había más. El padre, de nombre Ernesto, resultó ser una persona de carácter violento, un celoso compulsivo contra su propio hijo y un constante enemigo de la familia Llosa, a la que pertenecía su madre, y por obvias razones la única familia de la que se sentía parte el niño Vargas Llosa. A esos defectos, hay que sumarle el hecho de que la incipiente vocación literaria del autor era inaceptable para el padre, por considerarla no solo una pérdida de tiempo sino incluso una "mariconada", cuando no una excusa para la bohemia. Los constantes enfrentamientos entre padre e hijo terminaron con la reclusión de Mario Vargas Llosa en el colegio militar Leoncio Prado a los 14 años. Un colegio que no solía convocar a alumnos de clase media, como lo era el autor, salvo a manera de "castigo" de parte de sus familias. Vargas Llosa estudió ahí los años de Tercero y Cuarto de secundaria, pasando los fines de semana en casa de sus primos en la calle Diego Ferré en Miraflores, tratando de cruzarse lo menos posible con su padre, quien vivía en La Perla con su madre.

Al final de su etapa escolar, nuevamente la figura del padre resulta trascendente para marcar su destino literario. En las vacaciones de Cuarto a Quinto de secundaria, Mario Vargas Llosa consiguió un empleo en un diario limeño y trabajó ahí, dejándose seducir no solo por la escritura de crónicas policiales sino también por el ambiente desinhibido de la redacción, que solía concluir sus madrugadas de cierre en bares de poca monta o prostíbulos. El padre no quiso permitir que el hijo terminase en ese círculo vicioso, y decidió no permitirle trabajar más en el periódico. Pero el adolescente se opone a esa decisión y consigue viajar a Piura para concluir su secundaria al lado de su abuelo, lejos de la dictadura del padre, y dispuesto a obtener la libertad de seguir vinculado al periodismo, aunque no a la bohemia necesariamente.

La lucha de poder entre padre e hijo tendría aún una última bata1la, la batalla final, cuando a los 18 años Mario Vargas Llosa conoce a 
la tía Julia Urquidi, una pariente boliviana de la hermana de su madre, divorciada y mayor de 30 años. Lo que al principio parece una suerte de compañía mutua para ir al cine, se va convirtiendo poco a poco en un galanteo y finalmente en un amorío a espaldas de la familia. Cuando la familia se entera luego de este romance, en vez de distanciarse prudentemente la decisión de Mario Vargas Llosa fue la de casarse con la tía Julia, pese a la diferencia de edad (y sin considerar que en aquellos años a los 18 años uno aún no era mayor de edad). El enlace oficial resulta accidentado, en especial porque deben encontrar a un alcalde que haga la vista gorda ante la falta del poder legal que permitía a un joven menor de edad contraer matrimonio, y termina realizándose en un pintoresco pueblo de Ica. Al enterarse de esa desobediencia mayúscula, el padre amenaza al hijo e incluso lo busca con una pistola en la mano, para obligarlo a deshacer ese matrimonio. La única solución es enviar a la tía Julia donde unos parientes en Chile, mientras el joven Vargas Llosa realiza una serie de oficios (llega a contar siete simultáneos) que le permitan cierta independencia económica, rentar una casa pequeña y poder traer a su mujer con él. Y eso sucede. Luego viajarán juntos a París gracias a una magra beca de estudios, y con toda la ambición de convertirse en escritor, pero eso es otra historia. La historia que aquí contamos termina con el padre al fin derrotado, obligado a reconocer que su hijo ha conseguido la soberanía y la libertad sobre su dictadura convirtiéndose en un esposo, es decir, nivelándose con su padre.

Todos estos hechos han sido descritos, de manera extraordinaria, por el mismo autor en su libro de memorias El pez en el agua, de 1993. Para quienes conocen la obra de Vargas Llosa, las resonancias autobiográficas y la sombra del padre asoman de manera constante en los primeros libros. En su primera novela, La ciudad y los perros, la historia de su padre y el secuestro, además de la violencia y la no aceptación del hijo tímido y sensible, es trasladada al personaje más desdichado del libro, apodado el Esclavo (aunque es el protagonista Alberto quien se dedicará a la literatura en el colegio). Los recuerdos de sus años de bohemia en Piura suceden en el prostíbulo regentado por la Chunga en La casa verde, su segunda novela, y también en Conversación en La Catedral. Y en la novela La tía Julia y el escribidor, casi con lujo de detalles, se cuenta la historia de lo que he dado en llamar "la batalla final" que terminó con la abdicación del padre.

Sin embargo, más importante que estos raptos autobiográficos presentes en sus novelas, es la manera cómo Vargas Llosa utiliza el 
demonio personal de la mala relación con el padre, y su imperiosa necesidad de ejercer su soberanía y autoridad contra el poder autoritario, en todas sus obras. Después de todo, no son los detalles reales y autobiográficos los que harán al autor exorcizar los demonios, sino el poder transformador de la ficción. Basta con ver cómo ejerce la violencia física, a imitación de la violencia militar, el Jaguar en La ciudad y los perros para ver hasta qué plano se puede llevar esta pelea por el poder. El adolescente imita la violencia que ejercen contra él, la aprende y la utiliza para incorporarse en la sociedad. La lucha de poder solo es una prueba para discernir quiénes pueden integrar el mundo adulto (el Jaguar, Alberto) y quiénes no superan esas pruebas (el Esclavo). En la estupenda novela Conversación en La Catedral la figura del padre parece transfigurarse en la del dictador Odría, contra quien el universitario Zavalita se rebela políticamente, pero también ( $\mathrm{y}$ de manera más perturbadora) en el mismo padre de Zavalita, un peón del régimen, igual de autoritario con el hijo como lo es el dictador con el ciudadano, pero quien guarda un misterio que le es develado en esa conversación en un bar: su apodo Bolas de Oro, debido a que las tiene de adorno. El padre es homosexual. Ejerce el poder, pero no lo merece. Solo puede ejercerlo escondiendo su verdadera inclinación sexual, y por tanto su poder resulta una mascarada, una caricatura del poder real falocéntrico. Ese descubrimiento transforma la historia personal del protagonista por completo y reinvierte los papeles. Cuando quien ejerce el poder es un Bolas de Oro, entonces algo anda mal, todo es una mentira, un caos. La sociedad machista ha logrado imponer su autoridad a cambio de sabotear, limitar y hacer obscena y escondida la sexualidad de un hombre. Zavalita ya no tiene por qué rebelarse contra su padre. Al perder este su virilidad, al menos simbólicamente a través del apodo, pierde también su poder.

\section{La castración como traición}

La novela más interesante de Mario Vargas Llosa para comentar estos aspectos que relacionan el poder con el falocentrismo social, aparece en el año 1967 y se titula Los cachorros. En realidad, esa novela breve o cuento largo es producto de un ejercicio de estilo, en el cual a Vargas Llosa se le pide escribir un texto que pueda acompañar una serie de fotografías de perros en estado de violencia. Como en textos ante- 
riores (notablemente en sus cuentos "Los Jefes" o "El desafío" o "Día domingo", o en la novela La ciudad y los perros) Mario Vargas Llosa recurre a la adolescencia y los años escolares, años de formación del carácter y del descubrimiento de la arbitrariedad del poder adulto, social o familiar, así como de la necesidad de defender la libertad individual, para retratar a la sociedad machista y falocéntrica.

Sin embargo, en ninguna novela el tema ha sido trabajado de una manera tan explícita, casi de tesis, sin quitarle con eso méritos a una novela que, sin duda, quedará como una de las novelas cortas más notables del castellano (junto a Aura, de Carlos Fuentes, El perseguidor de Julio Cortázar, El coronel no tiene quien le escriba de García Márquez, El lugar sin límites de José Donoso o Los adioses de Juan Carlos Onetti).

El título de la novela alude no solo a las fotografías que ilustran el relato (que en futuras ediciones de la obra no aparecen publicadas) sino también a la condición de cachorros, crías de un animal feroz, que tienen los alumnos de un colegio de clase media alta limeña. Si en $L a$ ciudad y los perros la palabra "perro" con que se designa a los alumnos de Tercero, es sobre todo peyorativa, en este caso la calidad canina alude a la ferocidad con que los adultos se mueven en el mundo del poder social y económico, un mundo cruel, competitivo y duro donde los niños son "cachorros" educados desde pequeños para asumir su rol cuando les toque hacerlo. Estos cachorros están condenados, por estirpe, a seguir la línea de poder y tarde o temprano desplazar a sus padres, con el fin de continuar el linaje.

Entre todos los niños mencionados en la novela, el cachorro con mayor probabilidad de convertirse en un macho alfa es el recién ingresado Cuéllar. A todos los demás alumnos les llama la atención cómo la timidez con que ingresa al colegio va transformándose, poco a poco, en liderazgo. Para conseguir ser parte del equipo de fútbol, por ejemplo, Cuéllar se dedica íntegramente a practicar ese deporte en vacaciones, hasta convertirse en un crack. Lo mismo sucede en sus estudios. No cabe duda de que el cachorro Cuéllar está destinado a ser un poderoso dentro de la sociedad, y hará todo lo que necesita para probar todos los días que da la talla.

Sin embargo, un día infausto, luego de un partido de fútbol, un perro enorme (un auténtico perro, además, inconsciente de su poder y de su agresividad) que los curas del colegio tienen de mascota, se escapa e ingresa al gimnasio y ataca a Cuéllar, que está en las duchas. No se 
dice explícitamente, pero es obvio para todos los que visitan al amigo en el hospital que la sangre en el baño no proviene de la cara ni de las piernas o los brazos. ¿Dónde mordió el perro tan rabiosamente?

Poco a poco la verdad sale a flote: Cuéllar ha sido castrado por el perro. Ahora ya no es solo Cuéllar sino que arrastra un apodo cruel Pichulita Cuéllar.

Y aunque los resultados de esa castración no pueden verse en el corto plazo (al contrario, Cuéllar se beneficia con su accidente pues los padres se vuelven más permisivos, recibe mejores regalos y más dinero de propinas) a mediano y largo plazo se van notando más.

Pichulita Cuéllar va creciendo, junto a sus amigos, en medio de una aureola de misterio y de poder, regalado por esa suerte de inmunidad que le da el haber estado tan cerca de la muerte. Cuéllar es un cínico, es un descreído, es un temerario. Ya sea en los juegos suicidas con su auto o el desafío a las olas con su tabla de surf, en plena Semana Santa (cuando el mar está embravecido), Cuéllar parece un valiente, un hombre que no le teme a la muerte, dejando a sus amigos en la incómoda posición de observadores tímidos e incapaces de tener tan pocas expectativas en el futuro como las tiene su amigo. Obviamente, los cachorros esperan convertirse en perros machos y por eso se cuidan; Pichulita Cuéllar vive el presente porque el futuro como cachorro castrado es incierto.

Pasan los años, los niños se vuelve adolescentes, el colegio se termina y las primeras actividades sociales (como el baile de promoción) los va preparando para la vida social que les espera. Todos pasan la prueba, menos Cuéllar, quien se emborracha y choca su auto antes del baile. Cuando luego de eso llega la hora de conseguir novia, Cuéllar empieza a sentir los primeros latigazos de su condición minusválida. Al principio, puede esconder en su cinismo y su afán de libertad, de no estar atado a ningún compromiso, el temor de no poder cumplir frente a una mujer. Pero a medida de que sus amigos crecen, y sus amoríos se convierten en compromisos más serios, el solitario Pichulita Cuéllar es un lastre para los amigos y las enamoradas.

El punto de inflexión ocurre con la aparición de una chica preciosa en el barrio, una digna mujer para un cachorro dispuesto a convertirse en macho alfa, una chica destinada para un joven como Cuéllar. Su nombre es Teresita y de inmediato se fija en él tanto como él en ella. Empiezan los primeros rodeos, los galanteos, los chismes, y pronto 
es un hecho que la pareja debe consolidarse. No hay vuelta atrás. Las amigas se han encargado de aceptarla en el grupo, los amigos (aunque inquietos) también animan a Cuéllar. Pero es entonces que él duda. La presencia de Teresita ha ejercido cierta alquimia en él, que empieza a trabajar con su papá, piensa en estudiar, se preocupa más por el futuro, al tiempo que insiste con su padre en un supuesto tratamiento que podrá restituirle lo castrado. Pero cuando el tratamiento resulta una falsa alarma, esa pequeña esperanza se estrella contra el piso. Teresita aun está interesada en él, pero Cuéllar ha dejado de correr en esa pista. Sabe que no puede ser un esposo para ella, aunque tenga todo para hacerla feliz. Sin un pene, sin la capacidad ya no solo de la procreación sino de la penetración, no hay acceso al poder. Y por tanto, tampoco a Teresita, que pronto se aburre de la apatía (la rendición) de Cuéllar y se busca un novio más decidido. Un hombre de verdad.

Cuéllar sufre la desilusión, los amigos entienden lo que pasa y se lamentan con él, pero para las mujeres no hay dudas. Cuéllar no tiene agallas, no tiene lo que debe tener un hombre (no saben del accidente de infancia, no tienen idea de lo que dicen, pero viviendo en la sociedad machista pueden entender perfectamente que Cuéllar es un castrado no solo fisiológica sino psicológicamente). Al final, concluye una, "es un maricón".

La pérdida de Teresita enfrenta a Cuéllar con una realidad irrecusable. Solo es el primer paso, la primera aceptación, de que no es un cachorro ni podrá serlo mientras esté castrado. Es un adorno dentro de una sociedad donde el poder se rige por demostraciones de hombría, ya no de carreras de autos o arrojos en tablas de surf, sino de compromisos de macho. Pichulita Cuéllar debe regresar a la adolescencia, al punto exacto donde aun su castración no era un impedimento para ser un cachorro, y empieza a llenar su auto de chicos menores que él, para escándalo de sus amigos. Abandona el trabajo, deja sus ideas de ir a una universidad, no ve más a sus amigos (que se van casando, que van consiguiendo mejores empleos, a quienes les va creciendo la barriguita) y se dedica a una vida en eterno presente, al margen del poder social, de las mujeres, de los machos. Una vida que termina cuando estrella su auto en las peligrosas curvas de Pasamayo. Ni siquiera es necesario determinar si es un suicidio o un accidente. Pichulita Cuéllar ya había dejado de existir para la sociedad. Si en la novela de Moravia la diferencia en el tamaño de pene entre su padre y él, convierte al profesor de literatura en un vo- 
yeur, no un actor, imaginen lo que la falta de pene puede hacer por un hombre como Cuéllar. Simplemente, no puede jugar bajo las reglas de la sociedad machista. Le falta el equipo necesario. Cero opciones.

Un detalle resulta especialmente alegórico, un subrayado en esta historia de castración real y simbólica: el perro que muerde a Cuéllar y lo condena a dejar de ser un cachorro se llama "Judas".

A Cuéllar lo han traicionado.

\section{El enfrentamiento con el padre}

En Los cachorros, Cuéllar no debe enfrentarse con el padre. No están en igualdad de condiciones. El padre de Cuéllar lo protege, lo cuida, lo lamenta. Cuéllar no tiene futuro en la sociedad machista y falocéntrica, por lo tanto no se preocupa por establecer una lucha de poder. Vargas Llosa, el hijo, en cambio, sí ejerce esa lucha y solo consigue ganar la guerra cuando se casa con la tía Julia, es decir cuando le demuestra a su padre que está equipado con todo lo que tiene un hombre, es decir, no solo es capaz de sostener económicamente a una esposa sino que además de satisfacer sexualmente a una mujer guapa, divorciada y muchos años mayor que él. Sin embargo, para alguien que piensa como Vargas Llosa en el poder liberador de la ficción, ese triunfo real no tiene sentido si no hay un correlato en la ficción. Los cachorros no es esa novela. Tampoco lo es Conversación en La Catedral, aunque se acerca con la paradoja en la que vive envuelto Bolas de Oro, el padre del protagonista. No lo es, desde luego, La tía Julia y el escribidor, donde la narración de los capítulos autobiográficos (en contraparte con las descripciones de los radioteatros de Pedro Camacho) convierten al padre en un ser caricaturesco, sin mayor peligro. Aunque en todas estas novelas y otras más (como La guerra del fin del mundo, El Paraíso en la otra esquina o la última, El sueño del celta) el enfrentamiento contra el poder es perceptible, interesante, y nos conduce necesariamente al tema del enfrentamiento contra el padre, creo que la novela en la que Mario Vargas Llosa logra al fin, de forma contundente y lúcida, derrotar en la ficción a su padre es en una de sus mejores obras, publicada en el año 2000, es decir la extraordinaria novela La fiesta del Chivo.

Pero antes de entrar a esta novela, dos aclaraciones. 
Primero, en las novelas de Vargas Llosa, el amor idílico nunca es un motivo literario especialmente atractivo o interesante (ni siquiera en su "novela de amor" Las travesuras de la niña mala). La presencia de las chicas "decentes" y su contraparte, las prostitutas, tiene como saldo un triunfo de las segundas, que son personajes más atractivos siempre, desde la Pies Dorados. El amor por la tía Julia parece una novela de folletín, con poca emotividad, y en las novelas eróticas de don Rigoberto el indudable amor que siente por su mujer es sobre todo un pretexto para una serie de fantasías eróticas narradas. Pero si el amor no es un tema de alta importancia o desarrollo en la narrativa de Vargas Llosa, sí lo es el sexo. La sexualidad ha estado presente de manera intensa en todas las novelas de Vargas Llosa, desde La ciudad y los perros. Sin lugar a dudas, el sexo e incluso las perversiones sexuales es un tema que lo inquieta, que lo motiva, que le intriga. A veces aparece de una manera cruda, detonante, como en La casa verde o en La guerra del fin del mundo. Otras veces, es un delirio burlesco, como en Pantaleón y las visitadoras o Elogio de la madrastra. En ciertos casos, hay una reflexión sobre la libertad sexual (ya sea para tener sexo libre o abstenerse del sexo) como esos extremos opuestos y complementarios que son Paul Gauguin y su abuela Flora Tristan en El Paraíso en la otra esquina. En sus novelas hay zoofilia (en La ciudad y los perros), homosexualidad (en Historia de Mayta o El sueño del celta) y fantasías pornográficas (en Los cuadernos de don Rigoberto o Elogio de la madrastra). Hay mujeres exuberantes, hay mujeres cínicas, hay mujeres pervertidas o sometidas, hay mujeres que parecen ser hormonas sexuales capaces de despertar a los hombres de su letargo. Como sea, el sexo siempre aparece de manera contundente y compleja. La razón por la que el tema sexual ocupa un lugar tan importante en la literatura de Vargas Llosa resulta obvia cuando leemos algunas de sus opiniones sobre el sexo en otros libros. Por ejemplo, en su ensayo "El llamado del abismo", dedicado a La muerte en Venecia, de Thomas Mann, dice:

La razón, el orden, la virtud aseguran el progreso del conglomerado humano pero rara vez bastan para hacer la felicidad de los individuos, en quienes los instintos reprimidos en nombre del bien social están simplemente al acecho, esperando la oportunidad de manifestarse para exigir aquella intensidad y aquellos excesos que, en última instancia, conducen a la destrucción y a la muerte. El sexo es el territorio privile- 
giado en el que comparecen, desde las catacumbas de la personalidad, esos demonios ávidos de transgresión y de ruptura a los que, en ciertas circunstancias, es imposible rechazar pues ellos también forman parte de la realidad humana. Más todavía: aunque su presencia siempre entraña un riesgo para el individuo y una amenaza de disolución y violencia para la sociedad, su total exilio empobrece la vida, privándola de aquella exaltación y embriaguez — la fiesta y la aventuraque son también una necesidad del ser.

No es de extrañar, entonces, que este "territorio privilegiado" suela aparecer en las ficciones de Mario Vargas Llosa, no solo para completar el cuadro realista que pretende conseguir en cada una de ellas, sino, sobre todo, como una amenaza contra el orden, la razón y la virtud que no logran la felicidad humana sino que se imponen como un poder restrictivo y represivo. Un poder arbitrario contra el que, como ya hemos visto, algunos de los personajes de Vargas Llosa luchan ciegamente (el caso de Alberto en La ciudad y los perros) o conscientemente (el caso de Roger Casement en El sueño del celta). Aunque el sexo, en muchas de sus obras, sea una embriaguez que o bien destruye a los individuos y la sociedad misma (como en La casa verde), o bien los obliga a reprimirse para poder actuar con efecto en la sociedad machista (el caso de Bolas de Oro en Conversación en La Catedral) o quizá, con suerte, los exalta y les da a sus vidas una dimensión que no habían adquirido hasta ese momento (como en La guerra del fin del mundo con la pareja formada por Jurema y el periodista miope).

En segundo lugar, hay que decir algo sobre el tema del Dictador. Por Carlos Fuentes se ha conocido hace poco, aunque esa información circulaba de manera indirecta en varios textos, que el Boom Narrativo Latinoamericano solo tuvo un proyecto conjunto y fue hacer novelas sobre dictadores. Al parecer, el que se tomó más en serio la propuesta al inicio fue Gabriel García Márquez quien apuró con El otoño del patriarca. Desde luego, el tema atraía a Vargas Llosa sobremanera y ya lo había trabajado, de alguna forma, en Conversación en La Catedral. Pero la novela sobre dictadores que proyectaba Mario Vargas Llosa implicaba más horas de investigación y estudios, un proceso largo, abarcador y exigente que el autor se impone para ciertas novelas donde la documentación es la base. El dictador sobre el que Vargas Llosa quería escribir desde hacía décadas era Rafael Leonidas Trujillo, dictador de 
República Dominicana durante poco más de treinta años (desde 1930 hasta su asesinato en 1961).

La extensa documentación que había sobre Trujillo, que no solo incluía libros biográficos o históricos sino también recortes de diarios de época, fue minuciosamente revisada y fichada por Vargas Llosa durante años, en sucesivos viajes a República Dominicana, encontrándose con un material que lo excedía no solo en cantidad sino también en probabilidades. Si la idea de Ramón del Valle Inclán al escribir Tirano Banderas era crear la figura del dictador esperpéntico latinoamericano, ante una figura como Trujillo se quedó muy corto. No podía imaginarse de lo que era capaz, del absurdo impresionante al que podía llegar, un dictador como el personaje que había encontrado Vargas Llosa. El propio autor ha declarado que en su novela incluso debió "rebajar" el absurdo, el esperpento, del personaje real para no caricaturizarlo. Si hubiese contado los hechos tal y como se dieron en la realidad, hubiera sido un personaje inverosímil.

Ahora bien ¿por qué puede interesarle a Vargas Llosa escribir una novela sobre dictadores? Pues está claro que para alguien que tiene como eje de su narrativa la lucha contra el poder, la rebeldía contra un orden impuesto y la defensa de la soberanía e individualidad, una novela de dictadores era un territorio perfecto para llevar esa batalla. Y más aun un dictador como Trujillo, quien insistía en hacerles creer a sus habitantes que él era más que un gobernante, era un padre y al mismo tiempo un ser milagroso, con recursos casi mágicos y una leyenda que precedía cualquiera de sus acciones. El poder absoluto, el poder protector y el poder arbitrario son cualidades no solo de un dictador sino, también, de un padre violento e impositivo que aparece de la nada, rapta a su hijo y le impone un orden bajo la apariencia de protección. A través de esta novela durante tantos años acariciada, y escrita de manera apasionada, Mario Vargas Llosa iba a poder exorcizar al fin a su más antiguo demonio.

La fiesta del Chivo comienza con un regreso. El regreso de Urania, la chica que huyó de República Dominicana a los Estados Unidos para no ver más a su padre, y que ahora regresa porque el padre está postrado en una cama, incapaz de reconocerla y hablarle. Una hija frente a su padre postrado. Un tópico desde que Eneas encuentra a su padre Anquises en el infierno. El retorno no es fácil. Urania guarda un enorme rencor contra su padre, un intelectual sometido y vendido ante el poder 
de Trujillo, el cerebrito detrás de la dictadura. Ella regresa buscando explicaciones que no van a llegar, intentando perdonar o comprender a un padre al que no podrá perdonar y comprender jamás, pero al menos sí asistir a su muerte real para enterrarlo de una vez.

La relación especular entre Trujillo y el padre de Urania aparece, de manera brillante, desde el primer párrafo, cuando Urania llega a su país y se pregunta la razón por la que su padre le puso un nombre tan feo, una ocurrencia sin explicaciones. Y lo peor de todo es que su nombre, lo más privado que tenemos, nuestra identificación o identidad, es algo que ella rechaza profundamente como una imposición caprichosa:

No le habían hecho un favor sus padres; su nombre daba la idea de un planeta, de un mineral, de todo, salvo de la mujer espigada y de rasgos finos, tez bruñida y grandes ojos oscuros, algo tristes, que le devolvía el espejo.

En medio de esa divagación, dice:

Nunca lo sabrás. ¡Urania! Tan absurdo como afrentar a la antigua Santo Domingo de Guzmán llamándola Ciudad Trujillo. ¿Será también su padre el de la idea?

Tenemos entonces el enfrentamiento planteado desde las primeras líneas. Urania rechaza su nombre (y se alegra que desde que se fue a Estados Unidos no la llamen más así, sino Uri o miss Cabral) porque siente que es una impostura, una ocurrencia impuesta por el poder de su padre, del mismo modo como quizá por consejo e idea de su padre (como ya dijimos, el intelectual detrás del dictador), a la histórica ciudad de Santo Domingo se le impone el nombre falso de Ciudad Trujillo.

Para Urania, su padre y Trujillo, no solo por sus vínculos laborales en el gobierno, sino sobre todo por su abuso de poder y su intento de anular la individualidad de los demás, son la misma persona.

La novela narra el regreso de Urania, de 49 años. Pero también narra dos cosas más. Los últimos días de Trujillo como dictador, en medio de escaramuzas políticas por culpa de unos crímenes que EE.UU. le reclama, y también la alianza de un grupo de rebeldes que planea asesinar al dictador. Asistimos entonces a la narración tardía de una escena terrible durante los últimos días del dictador, narradas por la única testigo, Urania; a los tejemanejes políticos y los abusos de poder de quien se hace llamar el Benefactor o el Generalísimo; y los ajetreos de los conspiradores para asesinar a Trujillo en un nuevo intento de homicidio. 
El Chivo, el dictador Trujillo, creía tener un poder sobrenatural sobre los dominicanos. Algunos decían que era un instrumento del Ser Supremo y algunos lo llamaban el Maligno. Pero todos parecían atribuirle poderes mágicos y creaban mitos en torno a él. Trujillo sabía muy bien cómo alimentar esos mitos. Lo hacía usando todas las herramientas de la sociedad machista. El Chivo, ese animal mitológicamente asociado con la satisfacción y el desborde sexual, era una imagen recurrente que él fomentaba. A diferencia de su hijo Ramsés, que era más bien un donjuán, un conquistador de jovencitas y de estrellas de Hollywood, Trujillo alimentaba la fama de un fornicador insaciable, un hombre al que ninguna mujer de Santo Domingo podía negársele. Y al mismo tiempo, un hombre que era capaz de satisfacer a cualquier hembra, aun a sus setenta años. Sin embargo, la imagen que se nos muestra es una muy distinta al mito. Es la de un viejo con problemas de próstata, con incontinencia urinaria. Cada cierto tiempo, en medio de sus decisiones políticas absolutas y su cinismo de dictador, Trujillo verifica con horror que algunas gotas de orina se le han escapado. El Chivo, el gran macho, está perdiendo la confianza en sí mismo, y por ello decide intentar recuperarla. Y tendrá que hacerlo bajo las reglas de la sociedad falocéntrica que él ha sabido sostener para su favor. En un momento de optimismo, al ver que ha logrado vencer la incontinencia, exclama para sí mismo:

Mientras se inclinaba a ayudar a Dorothy Gittleman a levantarse, decidió, con todas las fuerzas de su alma: "Esta noche, en la Casa de la Caoba, haré chillar a una hembrita como hace veinte años". Le pareció que sus testículos entraban en ebullición y su verga empezaba a enderezarse.

Lamentablemente para Urania, la hembrita era ella. Una muchacha de 14 años, virgen, escolar y encima hija de uno de sus colaboradores más cercanos. ¿Podía haber una muestra mayor de poder absoluto? Sucedía que por diversión, por capricho, porque le gustaba ver a su "harem" de consejeros políticos disputarse sus favores, desde hacía unos días el Benefactor había empezado a atacar, a través de sus diarios, al padre de Urania. Este empezó a temer lo peor, la muerte o el destierro, sin entender por qué Trujillo lo había expulsado del círculo íntimo. Pronto, un celestino del dictador le presenta una solución para volver a recibir los favores del Benefactor: sacrificar a su hija para el goce del Chivo. Y la cobardía de Agustín Cabral no pudo decir que no. 
Mandó a su hija virgen, a lo que más adoraba en el mundo, a la Cabaña de Caoba, el lugar donde Trujillo ejercía de macho cabrío. La ingenua Urania asiste a lo que piensa será una fiesta de jovencitas, para enterarse luego que es la única invitada. Ingresa a la habitación del dictador y este empieza a seducirla y le da un beso introduciendo su lengua en ella. La inexperiencia de Urania excita al Benefactor. Así lo cuenta años después, en una cena, luego de su regreso: "Si el macho se excita, su sexo se endurece y crece. Cuando metió su lengua dentro de mi boca, su Excelencia se excitó". Pero iba a ir más allá de eso. La erección no cedía. La tumba sobre la cama y empieza a acariciarla, sin que ella sepa cómo responder. Entonces lo escucha decir: "Romper el coñito de una virgen siempre excita a los hombres". Ahí descubre Urania que las cosas no iban a hacer, ni siquiera, como una pareja romántica. Lo que iba a suceder ahí era la violación de una hembra de parte de un macho alfa. El macho de la manada, el padre de la patria y, de alguna manera su propio padre, iba a ejercer su poder autoritario y tomar su virginidad para alimentar su hombría.

Había aceptado que la hijita del senador Agustín Cabral viniera a la Casa de Caoba solo para comprobar que Rafael Leonidas Trujillo Molina era todavía, pese a sus setenta años, pese a sus problemas de próstata, pese a los dolores de cabeza que le daban los curas, los yanquis, los venezolanos, los conspiradores, un macho cabal, un chivo con un güevo todavía capaz de ponerse tieso y romper los coñitos vírgenes que le pusieran por delante.

Sin embargo, por más que Urania se sometiese al fin al vejamen, por más que le hiciera caso pese al asco y le chupara la verga anciana, el güevo no fue capaz de ponerse tieso. "Lo chupé, lo besé hasta las arcadas. Blando, blando. Yo le rogaba a Dios que se le parara", describe Urania.

Ahora la situación de Trujillo había cambiado. Ahora empezaba a temer que Urania le contase todo al padre, que este empezase a correr la voz de que al Chivo ya no se le paraba, que su poder autoritario sustentando en ser el macho alfa empezase a deteriorarse. Y ante la indignación y el temor, optó por humillar aun más a Urania. Se montó encima de ella y la desvirgó con los dedos. La sangre y los gritos no eran fingidos. Urania, traicionada por su padre, acababa de ser violada por el Benefactor y padre de la patria. 
Y entonces - dice Urania- Su Excelencia volvió a tenderse de espaldas, a cubrirse los ojos. Se quedó quieto, quietecito. No estaba dormido. Se le escapó un sollozo. Empezó a llorar.

El llanto del dictador, un llanto "por su próstata hinchada, por su güevo muerto, por tener que tirarse a las doncellas con los dedos". El poder del Chivo está acabado. Simbólicamente, sin saberlo, sin pretenderlo incluso, sin entenderlo, Urania ha logrado lo que decenas de conspiradores no pudieron hacer: quitarle el poder supremo al Padre de la Patria Nueva, el Chivo macho, y convertirlo en un anciano sin poder, sin erección, un castrado al que solo le queda la muerte. Por ello, no resulta extraño que luego de esa fiesta inconclusa, los rebeldes interceptaran el auto de Trujillo (como muchas veces antes lo habían logrado hacer) y dispararan todos los tiros contra el dictador. Pero esta vez, para su sorpresa, el ser supremo, el Maligno, no había podido escapar. Esta vez lograron matarlo. Porque, sin saberlo, no disparaban contra el Chivo Erecto y Todopoderoso sino contra un viejito lloroso, acosado por la próstata, incapaz de tener una erección y, por tanto, de ostentar ningún poder en la sociedad machista que él fomentaba.

Urania es, desde luego, una víctima del poder machista. Nunca más pudo tener relaciones con ningún hombre. Ni sentimientos. Era un témpano de hielo y les temía a los galanes, incluso a los que iban hacia ella con buenas intenciones. Se había apartado de la sociedad que la obligaba a tener relaciones sexuales. No quería saber nada con el abusivo mundo de machos poseedores del que había conocido, desde niña, la peor cara. Sin embargo, el final de la novela, con Urania mirando las estrellas y dándose tiempo para hacer las maletas, mientras decide retomar el contacto con los familiares que dejó en República Dominicana al huir dos semanas después de la violación, es un final de reconciliación. Trujillo ha muerto, su padre se está extinguiendo con mucho dolor en una cama (y ella no sabe si le guarda rencor aún o no) y ella, al fin, ha logrado contarles a sus primas y su tía aquello que guardó por años y que, una vez fuera, deja de ser una herida que se enraíza más y más en el secreto.

Urania ha contado una historia en la que ella es la única sobreviviente y los dos padres, los dos poderosos, han sido derrotados. La historia que cuenta Urania es su propia historia. Las historias que cuenta Mario Vargas Llosa son ficciones. Pero en ambos casos hay un 
punto de contacto: aquel que puede ser exteriorizado, materializado, expuesto públicamente, puede ser exorcizado porque ya no se oculta en el subconsciente donde crece sin límites. Hay que sacar al demonio afuera para matarlo y recuperar nuestra soberanía, el poder de nuestra libertad y el control de nuestras decisiones más allá de las obligaciones o imposiciones machistas y falocéntricas que nos impone la sociedad latinoamericana en que vivimos.

\section{OBRAS CITADAS}

Vargas Llosa, Mario. La fiesta del Chivo. Alfaguara, 2000.

"El llamado del abismo". En Mario Vargas Llosa, La verdad de las mentiras. Alfaguara, 2002.

"Prólogo". En Mario Vargas Llosa, La verdad de las mentiras. Alfaguara, 2002. 